\title{
Alterações anatômicas em folhas e raízes de Jatropha curcas $L$. cultivadas sob estresse salino ${ }^{1}$
}

\author{
Anatomical changes in the leaves and roots of Jatropha curcas L. cultivated under \\ saline stress
}

\author{
Gemima Manço de Melo ${ }^{2 *}$, Patrícia Carneiro da Cunha ${ }^{3}$, João Alves Ferreira Pereira ${ }^{4}$, Lilia Willadino ${ }^{5}$ \\ Cláudia Ulisses ${ }^{6}$
}

\begin{abstract}
Resumo - A espécie Jatropha curcas L. está entre as mais destacadas fontes de grãos oleaginosos, com baixa exigência hídrica e nutricional, sendo promissora para regiões áridas e semiáridas, em geral sujeitas à salinização do solo. Objetivou-se neste trabalho avaliar o efeito de diferentes concentrações salinas, sobre a anatomia de folhas e raízes de Jatropha curcas. Cinqüenta sementes foram semeadas em bandejas, e as plântulas transferidas para potes com capacidade para 5 litros, o ensaio foi conduzido em casa de vegetação. Após 21 dias da germinação, as plantas foram submetidas aos seguintes tratamentos salinos: 25; 50; 75; 100; 150 e $200 \mathrm{mM}$ de $\mathrm{NaCl}$, além do controle $(0 \mathrm{mM} \mathrm{de} \mathrm{NaCl})$, em delineamento inteiramente casualizado, com cinco repetições por tratamento. Ao final do $32^{\circ}$ dia de tratamento, a terceira folha e raízes, medindo aproximadamente 5 $\mathrm{cm}$ de comprimento, foram coletadas e fixadas em FAA 50. Seções transversais da porção mediana da nervura central da folha e da região mediana da raiz foram cortadas e coradas com safrablau. Foram observadas na folha redução no número de células do xilema e floema e alterações em sua distribuição, em função do aumento das concentrações de sal na solução. Nas raízes observou-se que, quanto mais alta a concentração salina, maior a lignificação das células xilemáticas e endodérmicas, e maior a redução no diâmetro e no número de elementos de vaso. Portanto, ocorrem alterações anatômicas em folhas e raízes das plantas quando cultivadas sob altas concentrações salinas.
\end{abstract}

Palavras-chave - Pinhão-manso. Morfologia. Cloreto de sódio.

\begin{abstract}
The species Jatropha curcas L. is among the most prominent sources of oilseeds, with low water requirement and nutrition, and promising to arid and semiarid regions, usually subject to soil salinization. The objective of this study was to evaluate the effect of different salt concentrations on the anatomy of leaves and roots of Jatropha curcas. Fifty seeds were sown in trays and the seedlings transferred to pots with a capacity of 5 liters, the test was conducted in a greenhouse. After 21 days of germination, the plants were subjected to the following saline treatments: $25 ; 50 ; 75 ; 100 ; 150$ and $200 \mathrm{mM} \mathrm{NaCl}$, and the control $(0 \mathrm{mM} \mathrm{NaCl})$ in a randomized design with five replicates per treatment. At the end of the 32 days of treatment, the third leaf and roots measuring approximately $5 \mathrm{~cm}$ in length, were collected and fixed in FAA 50. Transverse sections from the leaves middle portion and the middle region of the root were cut and stained with safrablau. Were observed the reduction in xylem and phloem leaf cells and changes in their distribution as a function of increasing concentrations of salt in the solution. In roots it was observed that the high salt concentration increased xylem cells and endoderm lignification and reduced diameter and number of vessel elements. Thus, the species studied has considerable anatomical changes in leaves and roots when grown under high salt concentrations.
\end{abstract}

Key words - Physic nut. Morphology. Sodium chloride.

\footnotetext{
* Autor para correspondência

Recebido para publicação em 31/08/2010; aprovado em 31/01/2011

Trabalho submetido e selecionado no primeiro Simpósio Brasileiro de Salinidade realizado de 12-15/10/2010 em Fortaleza, Ceará, Brasil; Pesquisa financiada pela CAPES e CNPq

${ }^{2}$ Programa de Pós-Graduação em Agronomia Melhoramento Genético de Plantas/UFRPE, Rua Dom Manoel de Medeiros s/n, Recife-PE, Brasil, 52.511-900, gemimamelo81@yahoo.com.br

${ }^{3}$ Bolsista CNPq, Programa de Pós-Graduação em Botânica/UFRPE, Rua Dom Manoel de Medeiros s/n, Recife-PE, Brasil, 52.511-900, patcunha28@hotmail.com

${ }^{4}$ Graduando do Curso de Agronomia/UFRPE, Rua Dom Manoel de Medeiros s/n, Recife-PE, Brasil, 52.511-900, jafp_hp2005@hotmail.com ${ }^{5}$ Instituto Nacional de Ciência e Tecnologia em Salinidade-INCTSal/CNPq, Departamento de Biologia/UFRPE, Rua Dom Manoel de Medeiros s/n, Recife-PE, Brasil, 52.511-900, 1ilia@pq.cnpq.br

${ }^{6}$ Departamento de Biologia/UFRPE, Rua Dom Manoel de Medeiros s/n, Recife-PE, Brasil, 52.511-900, claudia@nlink.com.br
} 


\section{Introdução}

A espécie Jatropha curcas L., conhecida popularmente como pinhão-manso, é bastante utilizada como medicinal (ARRUDA et al., 2004; CÁCERES et al., 2007) e, atualmente, está entre as mais promissoras fontes de grãos oleaginosos, por conter um teor de $40 \%$ de óleo em suas sementes, ter alto índice de produtividade, facilidade de manejo e de colheita das sementes, o que torna seu cultivo bastante atrativo e, especialmente, recomendado para um programa de produção de óleos vegetais (SLUSZZ; MACHADO, 2006). A espécie é exigente em insolação, com forte resistência à seca e baixa exigência nutricional, sendo considerada como uma opção agrícola para a região Nordeste (ANDRÉO-SOUZA et al., 2010; TEIXEIRA, 2005). Adapta-se a uma diversidade de ambientes e condições edafoclimáticas (SATURNINO et al., 2005), tais como, condições áridas e semiáridas, em geral, sujeitas a problemas de salinização do solo, sobretudo

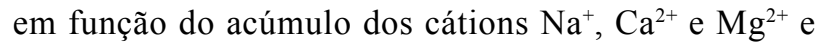
dos ânions $\mathrm{Cl}^{-}$e $\mathrm{SO}_{4}^{2-}$ (LACERDA, 2005).

A salinidade é um dos principais estresses que resultam em grande impacto no crescimento vegetal, alterando funções metabólicas, fisiológicas e anatômicas contribuindo para a redução da produtividade das culturas (ARAGÃO et al., 2010). Entre as alterações anatômicas estratégicas destaca-se a lignificação das paredes celulares (NEVES, 2009; OURIQUE et al., 2010), que provocam alterações na espessura dos tecidos; presença de estrias de Caspary, que atuam reduzindo o transporte de íons $\mathrm{Na}^{+}$pela via apoplástica (CASTRO et al., 2009); armazenamento de cristais de oxalato de cálcio nas células (HUNSCHE et al., 2010); e redução no número de células dos feixes vasculares, além de uma desorganização na acomodação dessas células (HU et al., 2005; CASTRO et al., 2009).

Considerando-se a escassez de publicações referentes aos efeitos da salinidade sobre a anatomia de plantas, de uma maneira geral, e em particular da espécie J. curcas L., o presente trabalho teve como objetivo identificar alterações na anatomia foliar e radicular de plantas submetidas a diferentes concentrações salinas.

\section{Material e métodos}

Cinquenta sementes de Jatropha curcas L. foram semeadas em casa de vegetação, em bandejas plásticas, sendo as plântulas transferidas para potes com capacidade para 5 litros, após a germinação. Passados 21 dias da germinação, as plantas foram submetidas, durante 32 dias, aos seguintes tratamentos salinos: $25 ; 50 ; 75 ; 100 ; 150$ e $200 \mathrm{mM}$ de $\mathrm{NaCl}$, além do controle $(0 \mathrm{mM}$ de $\mathrm{NaCl})$. $\mathrm{O}$ desenho experimental utilizado foi inteiramente casualizado com cinco repetições por tratamento. Ao final do $32^{\circ}$ dia do experimento com os tratamentos salinos, foram avaliadas seções transversais de raízes $(5,0 \mathrm{~cm})$ e da terceira folha das plantas. O material vegetal foi fixado em formol, álcool e ácido acético (FAA 50) (JOHANSEN, 1940). Para a confecção das lâminas histológicas, foram realizados cortes, à mão livre, em seções transversais da porção mediana da folha e da raiz, com o auxílio de lâmina cortante. Em seguida, as seções transversais foram clarificadas em hipoclorito de sódio $(\mathrm{NaOCl})(30 \%)$, enxaguadas com água destilada, coradas com safrablau (KRAUS; ARDUIN, 1997), montadas em glicerina (66\%) e lutadas com esmalte incolor. As seções transversais foram analisadas em imagens digitais obtidas através de câmera digital acoplada ao microscópio ótico Coleman modelo XSZ-107BN, projetando-se nas mesmas condições ópticas, as escalas correspondentes.

\section{Resultados e discussão}

As folhas de plantas de $J$. curcas apresentaram epiderme uniestratificada, com células de tamanho irregulares, paredes lisas, delgadas e com presença de cutícula. Abaixo da epiderme observou-se uma restrita camada de parênquima paliçádico bi-estratificado, compacto e parênquima esponjoso, constituído por cerca de oito camadas de células, irregulares, resultando em espaços celulares com várias dimensões (FIG. 1A). Nas células próximas ao feixe vascular destaca-se a presença de drusas (FIG. 1B). Um feixe semicircular formado por uma série de células de xilema e outra série de células de floema foi observado ao longo da nervura mediana (FIG. 1C). As células do floema mostraram-se organizadas em cordões, dispostos em vários estratos celulares e as células do xilema dispostas radialmente, com paredes espessas e maior afinidade tintorial (FIG. 1C e 1D). Características similares foram observadas em Jatropha molissima (Pohl) Baill. espécie nativa da região semiárida do nordeste brasileiro (LEAL; AGRA, 2005).

Os feixes vasculares, mais especificamente, o xilema, apresentaram redução no número de células nas plantas que receberam solução salina, bem como, uma desorganização na acomodação dessas células à medida que as concentrações de sais da solução aumentaram (FIG. 2A a 2F). Na espécie Triticum aestivum L. cv. Thasos., também foi observado redução no número de vasos xilemáticos em folhas submetidas a $120 \mathrm{mM}$ de $\mathrm{NaCl}$ (HU et al., 2005). Associadas às funções que as folhas desempenham nas plantas, estes 


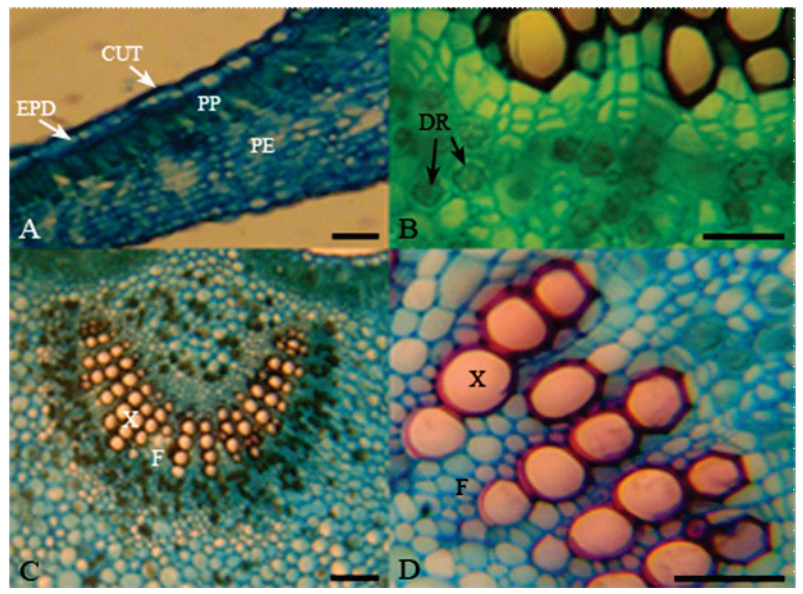

Figura 1 - Seções transversais de folha de plantas de Jatropha curcas L. cultivadas na ausência da solução salina (controle):

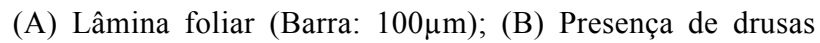
próxima aos feixes vasculares (Barra: $50 \mu \mathrm{m}$ ); (C) Disposição dos feixes vasculares na nervura mediana da folha (Barra: $100 \mu \mathrm{m}$; (D) Detalhe da organização das células de xilema e floema (Barra: $50 \mu \mathrm{m})$. (CUT $=$ cutícula; $D R=$ drusas; $\mathrm{F}=$ floema; $\mathrm{PE}=$ parênquima esponjoso; $\mathrm{PP}=$ parênquima paliçádico e $\mathrm{X}=$ xilema)

órgãos exibem variações apreciáveis na sua estrutura para manter a funcionalidade e, assim, melhorar a adaptabilidade das plantas aos diferentes ambientes (CASTRO et al., 2009). Essa variação está associada à resposta ao estresse induzido, pois nas plantas que não receberam tratamento com solução salina (controle) as células de xilema e floema ocorreram em maior quantidade, e na região do córtex da nervura mediana, localizada próximo aos feixes vasculares, observou-se a presença de células armazenando cristais (drusas) (FIG. 1B). Além das plantas controle, as plantas submetidas a $25 \mathrm{mM}$ de $\mathrm{NaCl}$ também apresentaram drusas (FIG. 2A). As drusas, cristais de oxalato de cálcio, podem constituir um reservatório para assegurar o suprimento de cálcio para os processos metabólicos, quando a absorção e a translocação desse cátion são reduzidas, devido ao estresse salino (HUNSCHE et al., 2010). O incremento da concentração de sal na solução resultou em redução na quantidade de cristais de cálcio armazenados nas células parenquimáticas sugerindo a utilização desse cátion no metabolismo da planta sob condições salinas.

As raízes das plantas de $J$. curcas possuem epiderme uniestratificada (FIG. 3A), contendo células com tamanhos irregulares. O parênquima cortical caracterizouse pela presença de várias camadas de células, delimitadas por poucos e pequenos espaços intercelulares (FIG. 3A).

O parênquima é um tecido que possui a função de armazenar substâncias, constituído de células vivas,

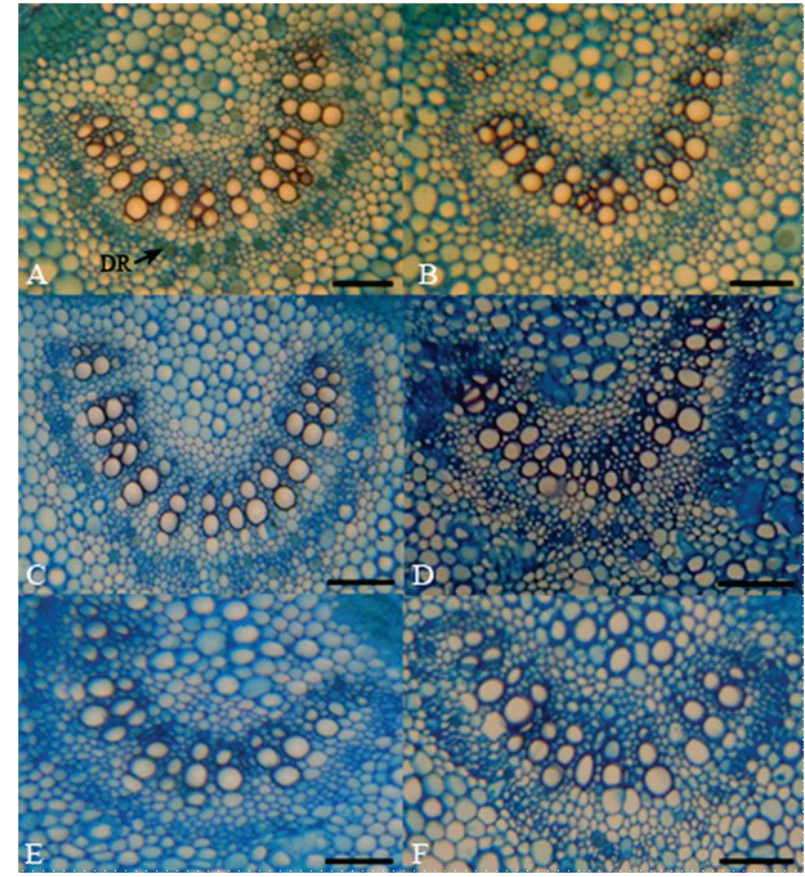

Figura 2 - Disposição dos feixes vasculares em seções transversais na nervura mediana da folha de plantas de Jatropha curcas L. cultivadas em diferentes soluções salinas: (A) 25; (B) 50; (C) 75; (D) 100; (E) 150 e (F) $200 \mathrm{mM}$ de $\mathrm{NaCl} .(\mathrm{DR}=$ drusas$)$. Barra: $100 \mu \mathrm{m}$

sendo considerado potencialmente meristemático, importante para o processo de cicatrização ou regeneração (APPEZZATO-DA-GLÓRIA; HAYASHI, 2006). Ainda de acordo com Appezzato-da-Glória e Hayashi (2006), o parênquima de reserva pode agir como meio para a planta evitar o estresse em determinados ecossistemas.

O feixe vascular mostrou-se composto por dois arcos de xilema (diarco) (FIG. 3C). Foi observado que as plantas cultivadas em menor concentração salina apresentavam o cilindro vascular com xilema pouco lignificado (FIG. 3B). Nas raízes das plantas tratadas com concentrações salinas superiores a $75 \mathrm{mM}$ de $\mathrm{NaCl}$ os elementos de vasos se caracterizaram pelo pequeno diâmetro (FIG. 3D e 3E), destacando-se na concentração de $200 \mathrm{mM}$ de $\mathrm{NaCl}$, condição de estresse severo, ocorreu simultaneamente à redução do diâmetro a redução do número de elementos de vasos das raízes (FIG. 3F). Comportamento similar foi observado em raízes de Populus $x$ canescens nas quais ocorreu uma redução das camadas e do diâmetro dos elementos de vasos, à medida que aumentava o período de exposição a solos salinizados (ESCALANTE-PÉREZ et al., 2009; JUNGHANS et al., 2006).

Verificou-se, também, que o incremento da concentração salina resultou em maior lignificação 


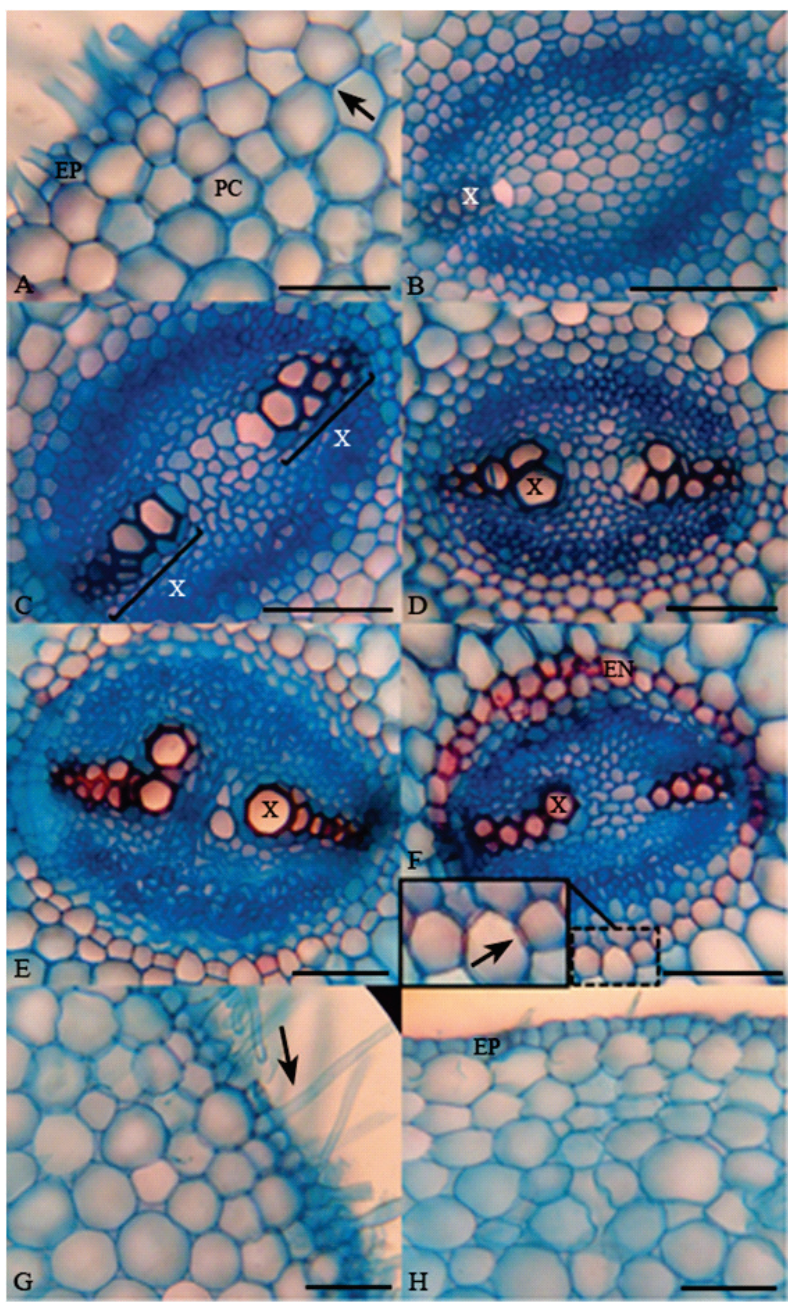

Figura 3 - Seções transversais de raiz de plantas de Jatropha curcas L. cultivadas em diferentes soluções salinas: (A) Epiderme uniestratificada, evidenciando o parênquima cortical e os espaços intercelulares (seta); (B) Raiz do tratamento controle, evidenciando o xilema com pouca lignificação; (C) Disposição das células de xilema de raiz cultivada com $25 \mathrm{mM}$ de $\mathrm{NaCl}$; (D) Organização das células xilemáticas de raiz cultivada com $75 \mathrm{mM}$ de $\mathrm{NaCl}$; (E) Organização das células xilemáticas lignificadas, de raiz cultivada com $100 \mathrm{mM}$ de $\mathrm{NaCl}$; (F) Organização das células xilemáticas e endodérmicas lignificadas, de raiz cultivada com $200 \mathrm{mM}$ de $\mathrm{NaCl}$, detalhando estrias de Caspary (seta); (G) Epiderme contendo tricomas (seta), de raiz cultivada com $25 \mathrm{mM}$ de $\mathrm{NaCl}$; (H) Epiderme com poucos tricomas, de raiz cultivada com $75 \mathrm{mM}$ de $\mathrm{NaCl}$. (EN = endoderme; $\mathrm{EP}=$ epiderme; $\mathrm{PC}=$ parênquima cortical e $\mathrm{X}=$ xilema). Barra $=50 \mu \mathrm{m}$

das células xilemáticas e endodérmicas (FIG. 3E e 3F). A lignina, metabólito secundário derivado do grupo dos fenilpropanóides, quando acumulada nas paredes celulares pode provocar alterações na espessura de tecidos submetidos a estresse (CASTRO et al., 2009). A exposição de raízes de Vigna unguiculata L. (OURIQUE et al., 2010) e Glycine max L. a elevadas concentrações de $\mathrm{NaCl}$ promoveu aumento no conteúdo de lignina que, segundo Neves (2009), constitui um mecanismo de adaptação ao estresse imposto pela salinidade.

Também foi evidenciada a presença de estrias de Caspary, contendo maior quantidade de lignina nas plantas submetidas a concentrações mais altas de sal (FIG. 3F). As estrias de Caspary formam uma barreira apoplástica para o fluxo de íons e de água (CASTRO et al., 2009) e quanto maior a deposição de lignina mais difícil se torna a perda radial de oxigênio (COLMER et al., 2005), elemento fundamental no processo de exclusão de sódio em plantas submetidas ao estresse salino.

A ocorrência de tricomas foi inversamente proporcional à concentração de cloreto de sódio (FIG. $3 \mathrm{G}$ e $3 \mathrm{H}$ ). Os tricomas são projeções da parede periclinal externa das células epidérmicas que desempenham a função de absorção de água, macro e micronutrientes e outros compostos (APPEZZATO-DA-GLÓRIA; HAYASHI, 2006; CASTRO et al., 2009), e sua redução, sugere uma diminuição da área de superfície de absorção das raízes em contato com a solução salina do substrato.

Diantedesses resultados, evidenciou-sequeaespécie Jatropha curcas L. apresentou alterações anatômicas nas folhas e raízes quando submetida a concentrações altas de sal. É importante destacar, entretanto, que não ocorerram alterações anatômicas nas plantas cultivadas por 32 dias nas concentrações iguais ou inferiores a $50 \mathrm{mM}$ de $\mathrm{NaCl}$.

\section{Conclusões}

1. Nas folhas de Jatropha curcas L. a medida que as concentrações salinas aumentam ocorre redução no número de células de xilema e floema, desorganização na distribuição dessas células e ausência de drusas;

2. As raízes das plantas submetidas ao estresse salino apresentam maior lignificação das células xilemáticas e endodérmicas e redução no diâmetro e no número de elementos de vaso;

3. Não há variações anatômicas nas plantas submetidas a concentrações de até $50 \mathrm{mM}$ de $\mathrm{NaCl}$ caracterizando tolerância desta planta ao estresse salino.

\section{Referências}

ANDRÉO-SOUZA, Y. et al. Efeito da salinidade na germinação de sementes e no crescimento inicial de mudas 
de pinhão-manso. Revista Brasileira de Sementes, v. 32, n. 02, p. 083-092, 2010.

APPEZZATO-DA-GLÓRIA, B.; HAYASHI, A. H. 2006. Raiz. In: APPEZZATO-DA-GLÓRIA, B.; CARMELLOGUERREIRO, S. M. Anatomia vegetal. 2. ed. Viçosa: Editora da Universidade Federal de Viçosa-UFV, 2006. Cap. 10 , p. $267-282$.

ARAGÃO, R. M. et al. Absorção, fluxo no xilema e assimilação do nitrato em feijão-caupi submetido à salinidade. Revista Ciência Agronômica, v. 41, n. 01, p. 100-106, 2010.

ARRUDA, F. O. et al. Cultivo de pinhão-manso (Jatropha curca L.) como alternativa para o semi-árido nordestino. Revista Brasileira de Oleaginosas e Fibrosas, v. 08, n. 01, p. 789-799, 2004.

CÁCERES, D. R.; PORTAS, A. A.; ABRAMIDES, J. E. Pinhãomanso. Disponível em: $<$ http://www.infobibos.com/Artigos/2007 3/pinhaomanso/index.htm>. Acesso em: 18 abril. 2008.

CASTRO, E. M. de; PEREIRA, F. J.; PAIVA, R. Histologia vegetal: estrutura e função de órgãos vegetativos. Lavras: Editora UFLA, 2009. 234p.

COLMER, T. D.; MUNNS, R.; FLOWERS, T. J. Improving salt tolerance of wheat and barley: future prospects. Australian Journal of Experimental Agriculture. v. 45, n. 11, p. 1425-1443, 2005.

ESCALANTE-PÉREZ, M. et al. Salt stress affects xylem differentiation of grey poplar (Populus x canescens). Planta. v. 229, n. 02, p. 299-309, 2009.

HU, Y.; FROMM, J.; SCHMIDHALTER, U. Effect of salinity on tissue architecture in expanding wheat leaves. Planta, v. 220, n. 06, p. 838-848, 2005.

HUNSCHE, M. et al. Effects of $\mathrm{NaCl}$ on surface properties, chlorophyll fluorescence and light remission, and cellular compounds of Grewia tenax (Forssk.) Fiori and Tamarindus indica L. leaves. Plant Growth Regulation, v. 61, n. 03, p. 253-263, 2010.
JOHANSEN, D. A. Plant microtechnique. New York: McgrawHill Book Co, 1940. 523p.

JUNGHANS, U. et al. Adaptation to high salinity in poplar involves changes in xylem anatomy and auxin physiology. Plant Cell Enviroment. v. 29, n. 08, p. 1519-1531, 2006.

KRAUS, J. E.; ARDUIN, M. Manual básico de métodos em morfologia vegetal. Rio de Janeiro: EDUR, 1997. 198p.

LACERDA, C. F. de. Interação salinidade x nutrição mineral. In: NOGUEIRA, R. J. M. C. et al. Estresses ambientais: danos e benefícios. Recife: UFRPE - Imprensa Universitária, 2005. Cap. 9 , p.127-137.

LEAL, C. K. A.; AGRA, M. de F. Estudo farmacobotânico comparativo das folhas de Jatropha molissima (Pohl) Baill. e Jatropha ribifolia (Pohl) Baill. (Euphorbiaceae). Acta Farmaceutica, v. 24, n. 01, p. 5-13, 2005.

NEVES, G. Y. S. Estresse salino e seus efeitos na lignificação de raízes de soja. 2009. 76 f. Tese (Doutorado em Ciências Biológicas) - Universidade Estadual de Maringá, Maringá.

OURIQUE, G. S. et al. Alterações anatômicas em plantas de feijão caupi (Vigna unguiculata (L.) Walp) submetidas a condições de saca e salinidade. In: REUNIÃO ANUAL DA SBPC, 62., 2010, Natal. Anais eletrônicos... Natal: SBPC UFRN. Disponível em: <http:// http://www.sbpcnet.org.br/livro/62ra/resumos/ resumos/4404.htm>. Acesso em: 08 mar. 2011.

SATURNINO, H. M. et al. Cultura do pinhão-manso (Jatropha curcas L.). Informe Agropecuário, v. 26, n. 229, p. 44-78, 2005.

SLUSZZ, T.; MACHADO, J. A. D. Características das potenciais culturas matérias primas do biodiesel e sua adoção pela agricultura familiar. In: ANAIS AGRENER, 6., 2006, Campinas. Anais da Agrener 6. Campinas: Unicamp, 2006. p.1-10.

TEIXEIRA, C. T. Potencialidades de oleaginosas para produção de biodiesel. In: Produção de oleaginosas para biodiesel. Informe agropecuário, v. 26, n. 229, p. 18-27, 2005. 